\title{
Hemodynamic effects of different types of pneumatic compression of the lower extremities during anesthesia induction: a prospective randomized controlled trial
}

\author{
Hyungsun Lim, Jin-Wan Kim, Kijae Lee, Donghak Seo, and Seonghoon Ko \\ Department of Anesthesiology and Pain Medicine, Chonbuk National University Medical School and Hospital, \\ Jeonju, Korea
}

\begin{abstract}
Background: The current study evaluated the hemodynamic effects of different types of pneumatic compressions of the lower extremities during anesthesia induction. In addition, the hemodynamic effects were compared between patients older than 65 age years and those aged 65 years or younger.

Methods: One hundred and eighty patients (90: $>65$ years and 90: $\leq 65$ years) were enrolled. Each age group of patients was randomly assigned to one of three groups; Group 1 (no compression), Group 2 (sequential pneumatic compression), and Group 3 (sustained pneumatic compression without decompression). Invasive blood pressure, cardiac index (CI), and stroke volume variation (SVV) were measured.

Results: In patients aged $\leq 65$ years, mean arterial pressure (MAP) and CI were significantly higher and SVV was lower in Group 3 compared to Group 1 before tracheal intubation, but there were no differences between Groups 1 and 2. However, there were no differences in MAP, CI, and SVV among the three groups in patients aged $>65$ years. The number of patients who showed a MAP $<60 \mathrm{mmHg}$ was less in Group 3 than Group 1 in patients aged $\leq 65$ years, but not in patients aged $>65$ years.

Conclusions: Sustained pneumatic compression of the lower extremities has more hemodynamic stabilizing effects compared to sequential compression during anesthesia induction in patients aged 65 years or younger. However, no difference between methods of compression was observed in patients older than 65 years.
\end{abstract}

Keywords: Aged; Anesthesia; Hemodynamics; Lower extremity; Pneumatic compression.

Corresponding author: Seonghoon Ko, M.D., Ph.D.

Department of Anesthesiology and Pain Medicine, Chonbuk National University Medical School and Hospital, 20 Gunji-ro, Deokjin-gu, Jeonju 54907, Korea

Tel: 82-63-250-1979, Fax: 82-63-250-1240

Email: shko@jbnu.ac.kr

ORCID: https://orcid.org/0000-0003-2742-9985

Received: July 21, 2017.

Revised: August 21, 2017 (1st); August 31, 2017 (2nd).

Accepted: September 4, 2017.

Korean J Anesthesiol 2018 October 71(5): 386-393

https://doi.org/10.4097/kja.d.18.27179

\section{Introduction}

Modern anesthetics have vasodilatory effect with minimal myocardial depression. The effect of anesthetics decrease systemic vascular resistance (SVR) and venous return. Furthermore, anesthesia decrease sympathetic activity before surgical stimulation $[1,2]$. Because anesthetics redistribute the blood from the central to the peripheral compartment secondary to vasodilatation for the reasons above, hemodynamic instability is common during the induction of general anesthesia and preparation for operation. The redistribution may decrease cardiac

(c) This is an open-access article distributed under the terms of the Creative Commons Attribution Non-Commercial License (http://creativecommons.org/ licenses/by-nc/4.0/), which permits unrestricted non-commercial use, distribution, and reproduction in any medium, provided the original work is properly cited. 
preload and results in a decrease in the stroke volume (SV) according to the Frank-Starling's law. Also, positive pressure ventilation decreases cardiac output result from effects on the right heart [3]. Consequently, blood pressure drops result from decreased cardiac output and SVR during general anesthesia induction.

In clinical practice, large volumes of fluid or short-acting cardiovascular active agent such as ephedrine may be administered to counteract anesthesia-induced hypotension. However, many previous reports have shown the risks of fluid overload although the role of perioperative fluid management remains under debate [4-7]. Additionally, the administration of ephedrine has a risk of myocardial ischemia due to severe tachycardia [8]. Therefore, prevention of the redistribution of blood during anesthesia might be a good option to avoid hemodynamic instability and the adverse effects of intravenous fluids and cardiovascular active agents. Although Trendelenburg positioning or passive legraising is a simple maneuver to increase the blood in the central compartment to restore cardiac preload, it is not feasible in many clinical situations. However, external compression of the lower extremities decreases the peripheral pooling of blood and augments venous return to increase central blood volume. Many previous reports have shown that the effects of pneumatic compression on the prevention of anesthesia- or position-related hypotension resulted from the peripheral redistribution of central blood volume [9-12]. Several types of pneumatic compression of the lower extremities, including pneumatic splint, intermittent compression, peristaltic compression, sequential compression, and military anti-shock trouser (MAST) are established interventions for various indications such as lymphedema, postthrombotic ulcers, arterial claudication, deep vein thrombosis, and severe trauma $[13,14]$.

We hypothesized that the use of pneumatic compression of the lower extremities would decrease hemodynamic instability during anesthesia induction and the effects may be different by the types of compression. In addition, the effects may be predominant in elderly patients. The primary purpose of this study was to compare the effects of pneumatic compression on the incidence of hypotension and hemodynamic variables by the types of compression during anesthesia induction. The secondary outcome of the study was comparison of the hemodynamic effects of pneumatic compression between patients older than 65 years and aged 65 years or younger.

\section{Materials and Methods}

This prospective randomized controlled study was approved by the Institutional Review Board of author's institution, and written informed consent was obtained for all participants. One hundred and eighty patients, American Society of Anesthesiolo- gists physical status I or II and aged 20 to 85 years, undergoing elective major operations that required invasive monitoring were enrolled. The patients that presented hypertension, cardiac arrhythmia, heart failure, vascular diseases, renal failure, CNS disorders, diabetes mellitus, alcohol or drug abuse, or a body mass index of $<18$ or $>35$ were excluded. Subjects were separated into those older than 65 years and those aged 65 years or younger initially. Each age group patients was randomly assigned by a computer-generated random number to one of three groups at preanesthetic visit according to the types of pneumatic compression of the lower extremities: Group 1 (control, no pneumatic compression), Group 2 (sequential pneumatic compression), and Group 3 (sustained pneumatic compression without decompression).

The anesthetic regimen was standardized with total intravenous anesthesia for all patients. Patients fasted for 8-12 $\mathrm{h}$ before surgery and received maintenance fluids. Glycopyrrolate $0.2 \mathrm{mg}$ was administered intravenously before transport to the operating theater. Before induction of anesthesia, a 20-G arterial catheter (Arterial cannula, Becton Dickinson Infusion Therapy System, USA) was inserted into the radial artery in the non-dominant hand after infiltration anesthesia with $2 \%$ lidocaine. The radial artery catheter was connected to the FloTrac ${ }^{\mathrm{TM}}$ transducer (Edwards Lifesciences, USA) coupled to both an anesthesia workstation (Primus Infinity ${ }^{\circledR}$ Empowered, Dräger, Germany) and $\mathrm{EV} 1000^{\mathrm{TM}}$ (software version 1.5, Edwards Lifesciences, USA) for hemodynamic measurements such as invasive blood pressure (IBP), SV, cardiac index (CI), and stroke volume variation (SVV). Pressure transducers were zeroed at the mid-axillary level to atmospheric pressure. Additionally, patients were monitored for electrocardiogram, pulse oximetry, temperature, capnography, peripheral nerve stimulator, and bispectral index (BIS). Baseline hemodynamic variables were measured before anesthesia induction. If the SVV of a patient was more than $12 \%$, the patient received $100 \mathrm{ml}$ of saline and $50 \mathrm{ml}$ increments until SVV presented less than $12 \%$. Patients were administered $2 \%$ lidocaine 2 $\mathrm{ml}$ intravenously with a tourniquet to prevent injection pain of propofol.

For the compression of the lower extremities, a pneumatic compression device (MK-400L, DS Maref, Korea) was used. The sleeves of the compression device, which has six air chambers, were applied from the foot to the thigh in all patients and compressed with $40 \mathrm{mmHg}$ of preset pressure circumferentially. After measurement of the baseline hemodynamic variables, pneumatic compression was started. The pneumatic compression was sequentially applied from the foot to the thigh to produce a milking action in Group 2. The total compression time of the device was $67 \mathrm{~s}$ with $10 \mathrm{~s}$ of compression time in each chamber and $7 \mathrm{~s}$ of full chamber compression time. One cycle of sequential compression was $80 \mathrm{~s}$ with $13 \mathrm{~s}$ of decompression time. 
In Group 3, $40 \mathrm{mmHg}$ of sustained compression of the lower extremities was maintained for the study periods. The compression pressure was not applied in Group 1 as the control group.

After BIS, vital signs, and hemodynamic variables were measured at the baseline, and anesthesia was induced by propofol (Fresofol MCT ${ }^{\circledR} 2 \%$, Fresenius Kabi, Austria) and remifentanil (Ultiva $^{\circledR}$, GlaxoSmithKline, Italy). Propofol and remifentanil were infused using an effect-site target-controlled infusion pump (Orchestra ${ }^{\circledR}$ Base Primea, Fresenius Vial, France) with the Marsh and Minto models, respectively. Initially, patients were induced with propofol $4 \mu \mathrm{g} / \mathrm{ml}$ and remifentanil $3 \mathrm{ng} / \mathrm{ml}$ of the effect-site concentration. After patients lost consciousness, $1.0 \mathrm{mg} / \mathrm{kg}$ of rocuronium was administered. The patients were manually ventilated via a face mask with air in oxygen and the investigators have tried to keep a fixed tidal volume (TV) of 8-10 $\mathrm{ml} / \mathrm{kg}$ under spirometric monitoring. Orotracheal intubation was performed $3 \mathrm{~min}$ after loss of consciousness (LOC). After endotracheal intubation, controlled mechanical ventilation was maintained with a TV of $8 \mathrm{ml} / \mathrm{kg}$ and an inspiratory to expiratory ratio of $1: 2$ without positive end-expiratory pressure. The ventilation frequency was set to maintain an end-tidal $\mathrm{PCO}_{2}$ range of 34-38 mmHg. Two minutes after endotracheal intubation, the effect-site concentrations of propofol and remifentanil were decreased to $2.5 \mu \mathrm{g} / \mathrm{ml}$ and $2.0 \mathrm{ng} / \mathrm{ml}$, respectively.

To evaluate the effects of the types of pneumatic compression on hemodynamic variables, IBP, heart rate (HR), CI, and SVV were measured at pre-anesthesia (baseline), at LOC, and at 1, 2, and $3 \mathrm{~min}$ after LOC and measured for $5 \mathrm{~min}$ with a 1-min interval after intubation. Additionally, BIS was recorded at the same time periods. If a patient showed a mean arterial pressure (MAP) of $<60 \mathrm{mmHg}$ or BIS $>60$, the patient received $10 \mathrm{mg}$ of ephedrine or the propofol concentration was increased in 0.5 $\mu \mathrm{g} / \mathrm{ml}$ increments, respectively. The number of patients who showed an MAP of $<60$ or $>130 \mathrm{mmHg}$ and $\mathrm{CI}$ of $<2.2$ or $>5.0$ $\mathrm{L} / \mathrm{min} / \mathrm{m}^{2}$ was recorded.

\section{Statistical analysis}

We considered a clinically significant difference in MAP, which was regarded as the primary endpoint, to be $\geq 10 \mathrm{mmHg}$. It was ascertained that 26 patients were required in each group to show a difference in MAP of $10 \mathrm{mmHg}$ for an expected standard deviation (SD) of $10 \mathrm{mmHg}$ with a significance level of 0.05 $(\alpha=0.05)$ and a power of $90 \%(\beta=0.10)$. The sample size was calculated by one-way analysis of variance (ANOVA) using SigmaPlot 12.5 (Systat Software Inc., USA). To allow for attrition, the sample size was enlarged to 90 in each age group.

Statistical analysis was performed with SigmaPlot 12.5. Continuous variables such as patient demographics, BIS, and hemodynamic variables were analyzed with one-way ANOVA, and the incidence of hypotension was analyzed using the Chi-square test. The Holm-Sidak method was used for multiple comparisons after the ANOVA test. All data are expressed as mean \pm SD. A P value of $<0.05$ was considered statistically significant.

\section{Results}

Six and three patients were excluded in patients aged $>65$ years and $\leq 65$ years, respectively. The data from 171 patients were analyzed (Fig. 1). All groups in each aged patients were comparable in terms of patient characteristics (Table 1). Before anesthesia induction, three patients aged $\leq 65$ years and 4 patients aged $>65$ years received crystalloid fluid to decrease SVV to less than $12 \%$, and the mean infused volumes were 200 and $183 \mathrm{ml}$, respectively. There were no differences in MAP, HR, $\mathrm{CI}, \mathrm{SVV}$, and BIS at the preanesthetic baseline values among the three groups in both patients aged $>65$ years and $\leq 65$ years.

MAP and CI were significantly decreased after anesthesia induction compared with the baseline values until intubation in all patients groups. In patients aged $\leq 65$ years, MAP and CI were significantly higher in the sustained pneumatic compression group (Group 3) compared with the control group (Group 1) from $1 \mathrm{~min}$ after loss of consciousness to just before endotracheal intubation, but there were no differences between Group 1 and Group 2 (sequential compression group) and Groups 2 and 3 . In patients aged $>65$ years, there were no differences in MAP and CI among the three groups (Figs. 2 and 3). SVV was increased after anesthesia induction in all patients. SVV was significantly lower in Group 3 than Groups 1 and 2 after anesthesia induction in patients aged $\leq 65$ years. However, there were no differences among the three groups at any time points in patients aged $>65$ years (Fig. 4). HR and BIS were not different by types of pneumatic compression at each time point in both ages of patients.

The number of patients who showed a MAP of $<60 \mathrm{mmHg}$ was lower in Group 3 than Group 1 in patients aged $\leq 65$ years, but there were no significant differences among the three groups in patients aged $>65$ years. There were no differences in the number of patients with a $\mathrm{CI}<2.2 \mathrm{~L} / \mathrm{min} / \mathrm{m}^{2}$ among the three groups in each age of patients. The number of patients who had MAP > $130 \mathrm{mmHg}$ or CI $>5.0 \mathrm{~L} / \mathrm{min} / \mathrm{m}^{2}$ were similar among the three groups after endotracheal intubation (Table 2).

\section{Discussion}

This study was conducted to compare the effects of two types of pneumatic compression of the lower extremities on hemodynamic variables during intravenous anesthesia induction. Furthermore, the effects were compared between patients older than 65 years and patients aged 65 years or younger. The authors 

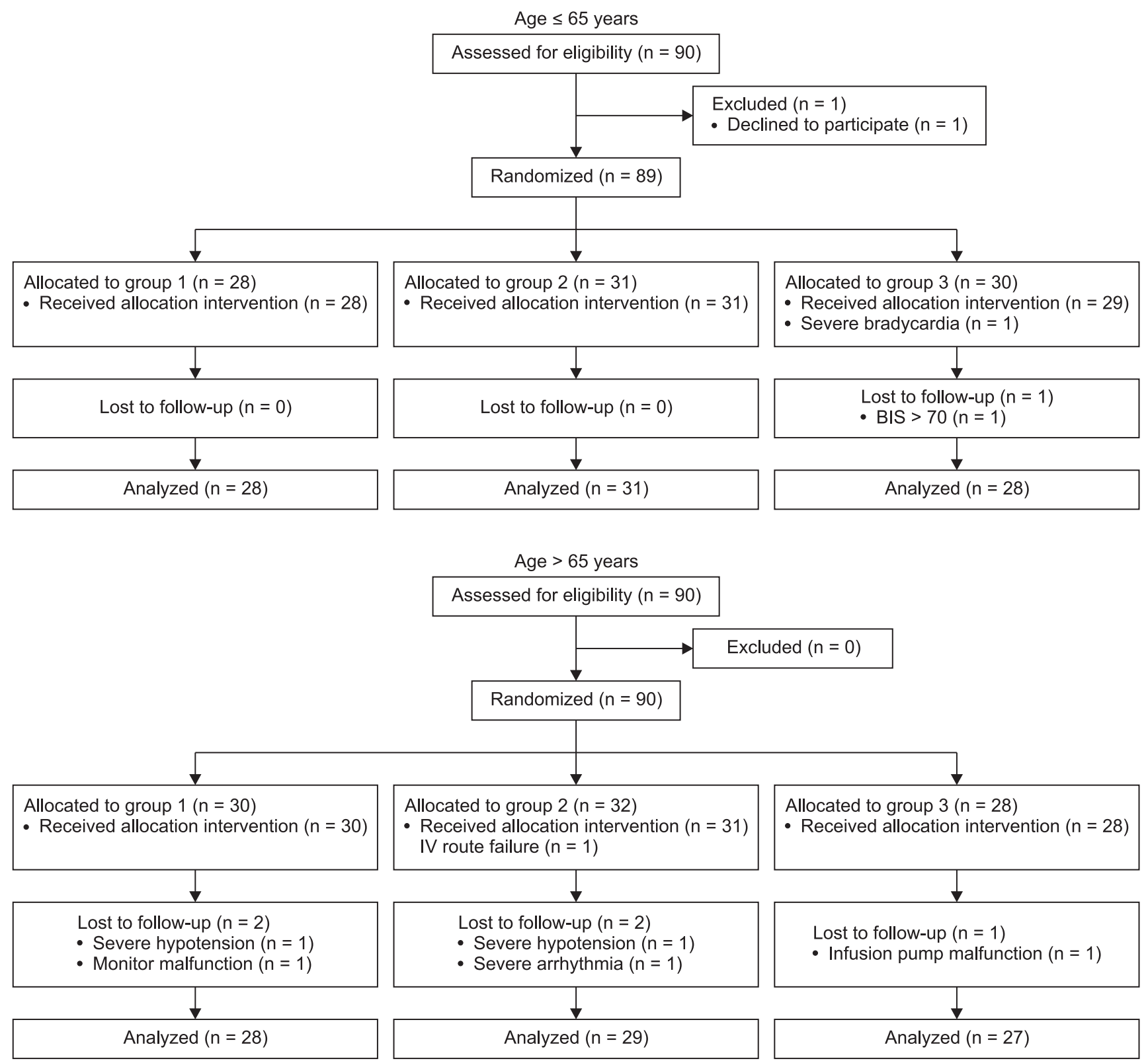

Fig. 1. Subject flow diagram. Groups 1, 2, and 3 in each age patient represent control, sequential compression, and sustained compression of the lower extremities, respectively. Three and two patients were discontinued the intervention by severe hypotension or arrhythmia and the hemodynamic monitor or target-controlled infusion pump malfunctions in patients aged older than 65 years, respectively. In patients aged 65 years or younger, one patient was excluded due to over 70 in bispectral index with propofol $4 \mu \mathrm{g} / \mathrm{ml}$ and remifentanil $3 \mathrm{ng} / \mathrm{ml}$ of the effect-site concentration.

Table 1. Patients Characteristics

\begin{tabular}{|c|c|c|c|c|c|c|c|c|}
\hline & \multicolumn{4}{|c|}{ Aged $\leq 65$ years } & \multicolumn{4}{|c|}{ Aged $>65$ years } \\
\hline & $\begin{array}{l}\text { Group 1 } \\
(\mathrm{n}=28)\end{array}$ & $\begin{array}{l}\text { Group 2 } \\
(\mathrm{n}=31)\end{array}$ & $\begin{array}{l}\text { Group } 3 \\
(\mathrm{n}=28)\end{array}$ & $P$ value & $\begin{array}{l}\text { Group 1 } \\
(\mathrm{n}=28)\end{array}$ & $\begin{array}{l}\text { Group 2 } \\
(\mathrm{n}=29)\end{array}$ & $\begin{array}{l}\text { Group } 3 \\
(\mathrm{n}=27)\end{array}$ & $P$ value \\
\hline Age (yr) & $53 \pm 6$ & $51 \pm 10$ & $52 \pm 8$ & 0.682 & $73 \pm 5$ & $71 \pm 4$ & $72 \pm 5$ & 0.172 \\
\hline Height $(\mathrm{cm})$ & $163 \pm 9$ & $165 \pm 8$ & $163 \pm 7$ & 0.559 & $161 \pm 9$ & $161 \pm 9$ & $159 \pm 7$ & 0.496 \\
\hline Weight (kg) & $63 \pm 12$ & $64 \pm 11$ & $63 \pm 10$ & 0.857 & $59 \pm 9$ & $58 \pm 11$ & $56 \pm 8$ & 0.589 \\
\hline $\mathrm{BMI}\left(\mathrm{kg} / \mathrm{m}^{2}\right)$ & $24 \pm 4$ & $24 \pm 3$ & $24 \pm 3$ & 0.983 & $23 \pm 3$ & $22 \pm 3$ & $23 \pm 4$ & 0.935 \\
\hline Gender (F/M) & $19 / 9$ & $19 / 12$ & $17 / 11$ & 0.825 & $18 / 10$ & $16 / 13$ & $16 / 11$ & 0.782 \\
\hline
\end{tabular}

Data are shown as mean \pm SD. Group 1,2, and 3 are control, sequential, and sustained pneumatic compression groups, respectively. 

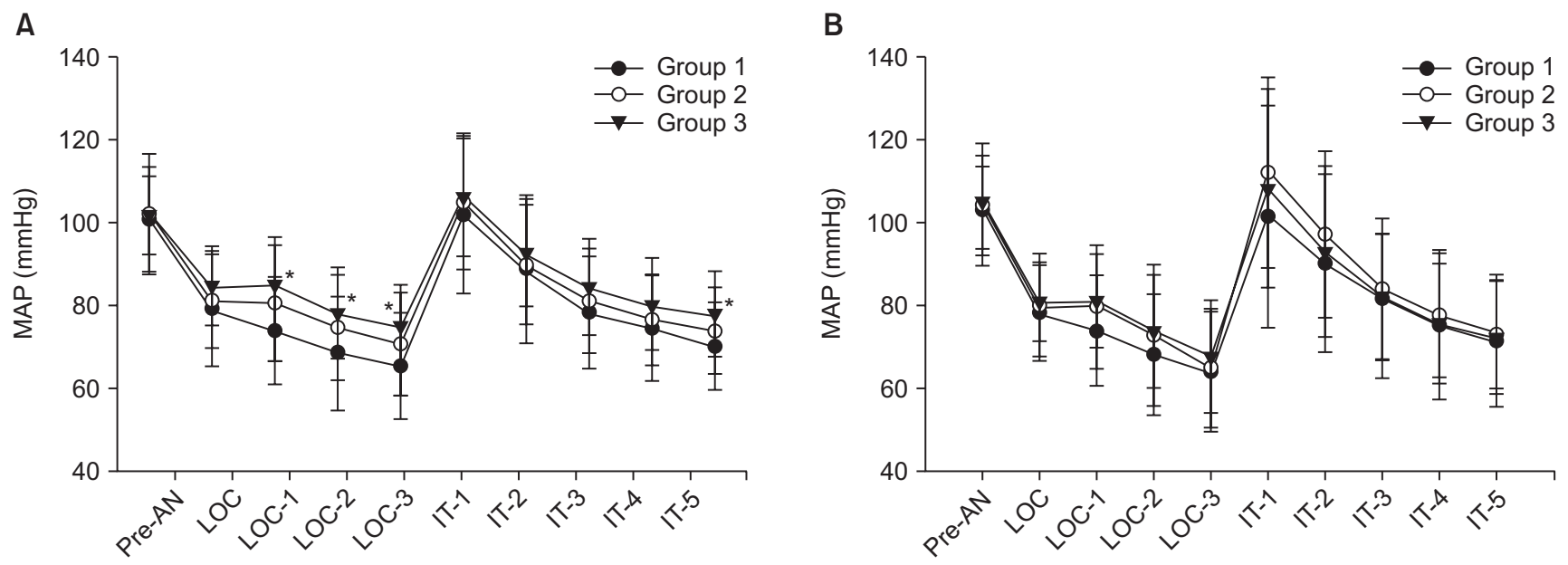

Fig. 2. Patients treated with sustained pneumatic compression of the lower extremities (Group 3) had significantly higher mean arterial pressure (MAP) 1, 2, and 3 min after loss of consciousness (LOC) and 5 min after intubation (IT) compared with the control group (Group 1), but there were no differences between Group 1 and Group 2 (sequential compression) in patients aged 65 years or younger (A). However, differences were not observed among the three groups in patients older than 65 years (B). Pre-AN: preanesthetic baseline. ${ }^{*} \mathrm{P}<0.05$ compared with Group 1.
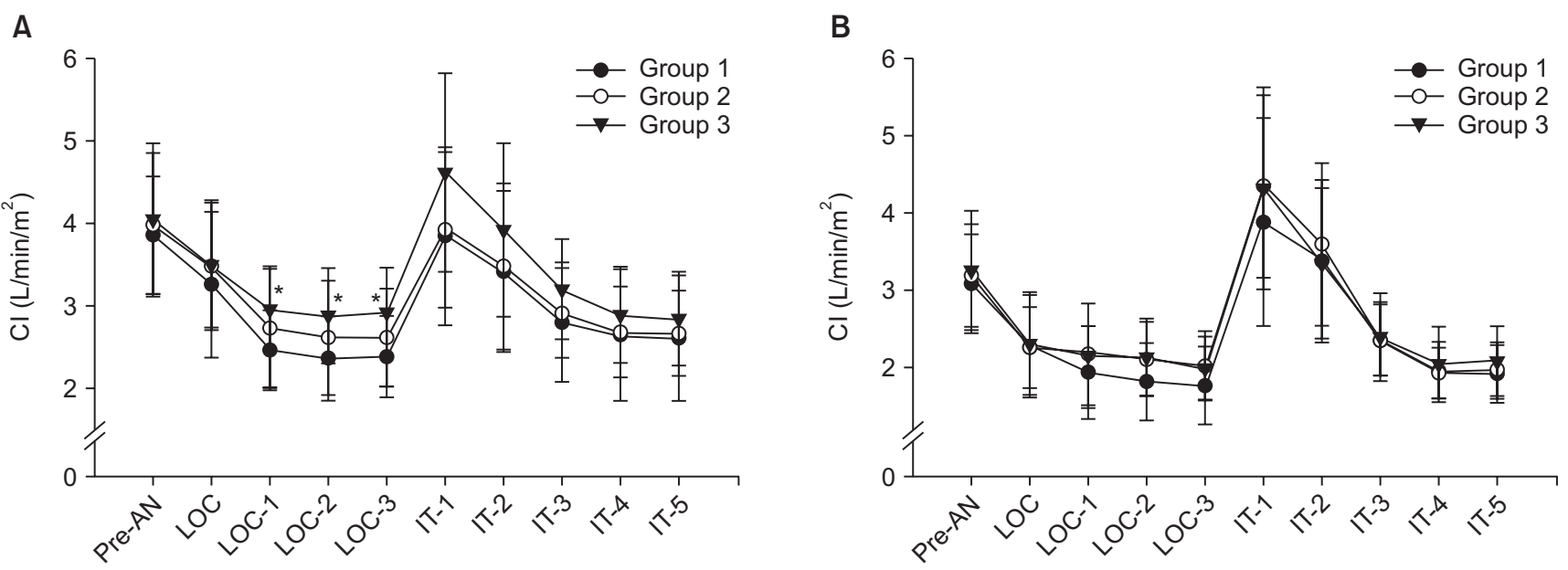

Fig. 3. Cardiac index (CI) decreased after induction of anesthesia in the three groups. However, CI were significantly higher in Group 3 (sustained pneumatic compression) compared with Group 1 (control) 1, 2, and 3 min after loss of consciousness (LOC) in patients aged 65 years or younger (A). There was no difference in CI among the three groups in patients older than 65 years (B). Pre-AN: preanesthetic baseline, IT: intubation. ${ }^{*} \mathrm{P}<0.05$ compared with Group 1.

hypothesized that sustained compression is more effective for preventing hemodynamic instability than sequential compression because venous blood can be pooled in the lower extremities during the decompression period of sequential compression. Because hemodynamic instability is more common and severe in elderly patients than younger patients during anesthesia induction, the authors speculated that the hemodynamic effects of pneumatic compression are greater in elderly patients. In the current study, sustained pneumatic compression more effectively prevented the decrease in MAP and CI and the increase in SVV than sequential pneumatic compression in patients aged $\leq$ 65 years. However, unlike the authors' hypothesis, the hemody- namic effects of pneumatic compression were not observed in elderly patients regardless of types of compression.

Although there are several types of pneumatic compression, two types of pneumatic compressions, sequential and sustained compressions, were compared in this study. Sequential pneumatic compression is a variation of intermittent pneumatic compression, using sequential compression from the foot upwards and decompression cycles. Because intermittent pneumatic compression is most commonly used in the prevention of deep venous thrombosis, most previous studies that evaluated the effects of pneumatic compression on hemodynamic instability related to spinal anesthesia $[9,15]$, operation position[11], and 
A

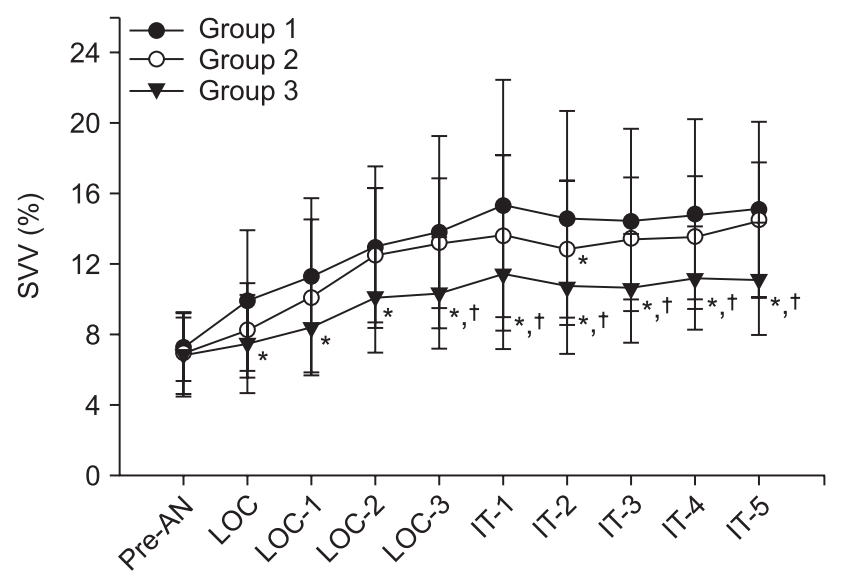

B

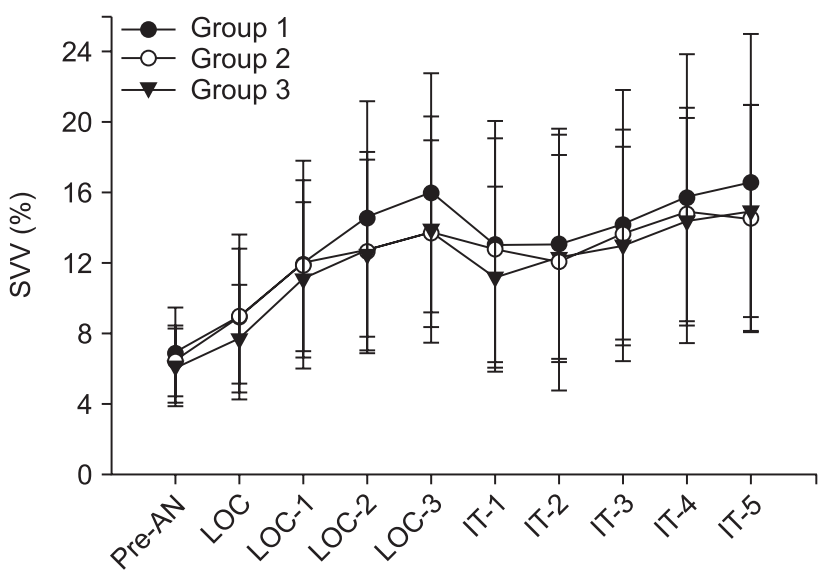

Fig. 4. Stroke volume variation (SVV), a parameter of preload, was significantly lower in the sustained pneumatic compression group (Group 3) compared with the control (Group 1) after anesthesia induction, but there were no differences between Group 1 and Group 2 (sequential pneumatic compression) in patients aged 65 years or younger (A). Differences were not observed among the three groups in patients older than 65 years (B). PreAN: preanesthetic baseline, LOC: loss of consciousness, IT: intubation. ${ }^{*} \mathrm{P}<0.05$ compared with Group $1 .{ }^{\dagger} \mathrm{P}<0.05$ compared with Group 2.

Table 2. Number of Patients Who Showed Hemodynamic Instability

\begin{tabular}{|c|c|c|c|c|c|c|c|c|c|}
\hline & & \multicolumn{4}{|c|}{ Aged $\leq 65$ years } & \multicolumn{4}{|c|}{ Aged $>65$ years } \\
\hline & & $\begin{array}{l}\text { Group 1 } \\
(\mathrm{n}=28)\end{array}$ & $\begin{array}{l}\text { Group 2 } \\
(\mathrm{n}=31)\end{array}$ & $\begin{array}{l}\text { Group } 3 \\
(\mathrm{n}=28)\end{array}$ & $P$ value & $\begin{array}{l}\text { Group 1 } \\
(\mathrm{n}=28)\end{array}$ & $\begin{array}{l}\text { Group 2 } \\
(\mathrm{n}=29)\end{array}$ & $\begin{array}{l}\text { Group 3 } \\
(\mathrm{n}=27)\end{array}$ & $P$ value \\
\hline \multirow[t]{2}{*}{ MAP (mmHg) } & $<60$ & 9 & 6 & $1^{*}$ & 0.022 & 11 & 11 & 10 & 0.955 \\
\hline & $>130$ & 3 & 1 & 4 & 0.322 & 5 & 5 & 8 & 0.451 \\
\hline \multirow[t]{2}{*}{$\mathrm{CI}\left(\mathrm{L} / \mathrm{min} / \mathrm{m}^{2}\right)$} & $<2.2$ & 8 & 8 & 4 & 0.401 & 20 & 17 & 14 & 0.318 \\
\hline & $>5.0$ & 3 & 5 & 3 & 0.767 & 5 & 10 & 9 & 0.306 \\
\hline
\end{tabular}

Group 1, 2, and 3 are control, sequential, and sustained pneumatic compression groups, respectively. MAP: mean arterial pressure, CI: cardiac index. *Adjusted $\mathrm{P}=0.015$ vs. Group 1.

surgery $[10,16]$ have used intermittent pneumatic compression. However, there has been no previous study that compared the effects by types of compression. It may be inferred from our results that sustained pneumatic compression may be more effective than intermittent pneumatic compression in perioperative hemodynamic instability related to spinal anesthesia, sitting position, and pneumoperitoneum. In clinical practice, sustained pneumatic compression of the lower extremities is used in severe traumatized patients or post-varicose vein operation. Sustained pneumatic compression is physically similar to the leg portion of MAST, but different in pressure. Because MAST is inflated with pressures of up to $100 \mathrm{mmHg}$, it can increase SVR as well as preload [17]. However, most previous studies that evaluated hemodynamic effects of pneumatic compression of the lower extremities were applied $40-60 \mathrm{mmHg}[9,10,12,16]$. SVR was not expected to increase similar as MAST with lower pressure $(40 \mathrm{mmHg})$ application in our study. If a higher pressure was applied in both sustained and sequential compressions in the current study, more hemodynamic stabilizing effects may be expected through increases in preload and SVR. Although the use of a higher pressure as MAST is not optimal because it potentially impedes overall blood supply and venous return, high-pressure compression may be applicable for short periods such as induction of anesthesia. One question remains whether low-pressure pneumatic compression can squeeze blood in the deep veins of the lower extremities. Therefore, further investigation is needed for an effective compression pressure.

Although intermittent pneumatic compression is a simple and reliable technique that increases the blood returning from the lower extremities, there have been few controlled studies to determine the increase in the central blood volume. Estimates of the recruited blood volumes from the lower extremities are variable in the literature. One study reported that an average of $107 \mathrm{ml}$ of blood can be moved by $50 \mathrm{mmHg}$ of sequential compression of the ankle and the calf [18]. Because thigh-high compression sleeves were used in the current study, a greater volume of venous return is expected than in a calf-high compression. In the other study, patients treated with thigh-high peristaltic 
pneumatic compression received $693 \mathrm{ml}$ of crystalloids less than the placebo compression group [12]. These results suggest that pneumatic compression of the lower extremities significantly reduces the fluid demand result from increased central blood volume. Unger and Feiner [19] observed that intermittent pneumatic compression increased central venous pressures, pulmonary artery pressures, and pulse pressures. Although they did not measure stroke volume, they suggested that the increased pulse pressures reflected an increased stroke volume. In the current study, CI was decreased to $62 \%$ of the baseline value in control group patients but, to $73 \%$ in sustained compression group patients at just before intubation in patients aged 65 years or younger. The difference of CI between the two groups could be due to the difference in stroke volume because the heart rates were similar in the two groups. Furthermore, SVV, a parameter of predicting fluid responsiveness, was significantly less increased in patients with sustained compression compared with control patients.

In the current study, the hemodynamic stabilizing effects of sustained pneumatic compression were predominant in patients aged $\leq 65$ years, but the effects were not observed in patients aged $>65$ years. The authors speculated the reasons for the difference. Firstly, the volume of recruited blood from the lower extremities in elderly patients were less than those of younger patients because of decreased muscle mass of the lower extremities. Secondly, the anesthetics-induced cardiac depression effect was more severe in elderly patients. The effect masks the hemodynamic stabilizing effects of pneumatic compression because CI was more decreased in elderly patients than younger patients. Most previous studies that investigated the pneumatic compression of the lower extremities examined young patients with intermittent or sequential compression as Group 2 aged $\leq$ 65 years. The studies showed hemodynamic stabilizing effects unlike our results. The authors considered that the discrepancy may be caused by relatively lower pressure and higher age in the current study.

Fluid loading or administration of cardiovascular active agent such as ephedrine or phenylephrine to treat anesthesia-induced hypotension causes minimal risk in healthy patients. Because application of pneumatic compression is more complicating process in simple anesthetic induction, routine use of pneumatic compression is limited in healthy patients. However, administration of fluid or vasoactive drugs should be avoided in some cases. Although the effects of sustained pneumatic compression were only $10 \mathrm{mmHg}$ of MAP differences observed and limited in aged $<65$ years old, it may work as alternative technique for avoiding fluid or vasoactive drugs administration. In addition, hypertension should also be avoided as well as hypotension during anesthesia induction. In the current study, there were no differences the number of patients who had MAP $>130$ $\mathrm{mmHg}$ among 3 groups. Also, the average MAP was similar after tracheal intubation although the incidence of hypotension was low in sustained pneumatic compression groups in patients aged $\leq 65$ years. Therefore, application of sustained pneumatic compression would be a good option to prevent hypotension without increasing incidence of hypertension during anesthesia induction.

There are two limitations in the current study. First, the preanesthetic baseline values of SVV were used as a preload parameter during spontaneous breathing. SVV is considered to unreliable in patients with spontaneous breathing. However, most patients received mechanical ventilation with a fixed TV of 8-10 $\mathrm{ml} / \mathrm{kg}$ under spirometric monitoring after propofol administration. Four percent of the patients (7 of 171) received fluid loading using preanesthetic SVV values before anesthesia induction in the current study. The main outcomes of the current study are hemodynamic changes after anesthesia induction and those before the beginning of operation. Therefore, the effect of preanesthetic SVV values and operation type were limited. Second, we could not determine why the results of the effects of sustained compression were different between elderly and younger patients. If we measured SVR, SV, and right ventricular volume using a pulmonary artery catheter and echocardiography, the cause may be clarified. In addition, the effects of compression pressure on SVR would be specified.

In conclusion, sustained pneumatic compression of the lower extremities has more hemodynamic stabilizing effects compared with sequential compression during intravenous anesthesia induction in patients aged 65 years or younger. However, the effects are not observed in patients older than 65 years.

\section{ORCID}

Hyungsun Lim, https://orcid.org/0000-0002-6379-9302

Seonghoon Ko, https://orcid.org/0000-0003-2742-9985

\section{References}

1. de Wit F, van Vliet AL, de Wilde RB, Jansen JR, Vuyk J, Aarts LP, et al. The effect of propofol on haemodynamics: cardiac output, venous return, mean systemic filling pressure, and vascular resistances. Br J Anaesth 2016; 116: 784-9.

2. Sellgren J, Pontén J, Wallin BG. Characteristics of muscle nerve sympathetic activity during general anaesthesia in humans. Acta 
Anaesthesiol Scand 1992; 36: 336-45.

3. Lansdorp B, Hofhuizen C, van Lavieren M, van Swieten H, Lemson J, van Putten MJ, et al. Mechanical ventilation-induced intrathoracic pressure distribution and heart-lung interactions*. Crit Care Med 2014; 42: 1983-90.

4. Corcoran T, Rhodes JE, Clarke S, Myles PS, Ho KM. Perioperative fluid management strategies in major surgery: a stratified meta-analysis. Anesth Analg 2012; 114: 640-51.

5. Holte K, Sharrock NE, Kehlet H. Pathophysiology and clinical implications of perioperative fluid excess. Br J Anaesth 2002; 89: 622-32.

6. Noblett SE, Snowden CP, Shenton BK, Horgan AF. Randomized clinical trial assessing the effect of Doppler-optimized fluid management on outcome after elective colorectal resection. Br J Surg 2006; 93: 1069-76.

7. Boland MR, Noorani A, Varty K, Coffey JC, Agha R, Walsh SR. Perioperative fluid restriction in major abdominal surgery: systematic review and meta-analysis of randomized, clinical trials. World J Surg 2013; 37: 1193-202.

8. Gamlin F, Freeman J, Winslow L, Berridge J, Vucevic M. The haemodynamic effects of propofol in combination with ephedrine in elderly patients (ASA groups 3 and 4). Anaesth Intensive Care 1999; 27: 477-80.

9. Adsumelli RS, Steinberg ES, Schabel JE, Saunders TA, Poppers PJ. Sequential compression device with thigh-high sleeves supports mean arterial pressure during Caesarean section under spinal anaesthesia. Br J Anaesth 2003; 91: 695-8.

10. Kurukahvecioglu O, Sare M, Karamercan A, Gunaydin B, Anadol Z, Tezel E. Intermittent pneumatic sequential compression of the lower extremities restores the cerebral oxygen saturation during laparoscopic cholecystectomy. Surg Endosc 2008; 22: 907-11.

11. Kwak HJ, Lee JS, Lee DC, Kim HS, Kim JY. The effect of a sequential compression device on hemodynamics in arthroscopic shoulder surgery using beach-chair position. Arthroscopy 2010; 26: 729-33.

12. Kiefer N, Theis J, Putensen-Himmer G, Hoeft A, Zenker S. Peristaltic pneumatic compression of the legs reduces fluid demand and improves hemodynamic stability during surgery: a randomized, prospective study. Anesthesiology 2011; 114: 536-44.

13. Chen AH, Frangos SG, Kilaru S, Sumpio BE. Intermittent pneumatic compression devices -- physiological mechanisms of action. Eur J Vasc Endovasc Surg 2001; 21: 383-92.

14. Helmi M, Gommers D, Groeneveld AB. A review of the hemodynamic effects of external leg and lower body compression. Minerva Anestesiol 2014; 80: 355-65.

15. Sujata N, Arora D, Panigrahi BP, Hanjoora VM. A sequential compression mechanical pump to prevent hypotension during elective cesarean section under spinal anesthesia. Int J Obstet Anesth 2012; 21: 140-5.

16. Schwenk W, Böhm B, Fügener A, Müller JM. Intermittent pneumatic sequential compression (ISC) of the lower extremities prevents venous stasis during laparoscopic cholecystectomy. A prospective randomized study. Surg Endosc 1998; 12: 7-11.

17. Gaffney FA, Thal ER, Taylor WF, Bastian BC, Weigelt JA, Atkins JM, et al. Hemodynamic effects of Medical Anti-Shock Trousers (MAST garment). J Trauma 1981; 21: 931-7.

18. Janssen H, Treviño C, Williams D. Hemodynamic alterations in venous blood flow produced by external pneumatic compression. J Cardiovasc Surg (Torino) 1993; 34: 441-7.

19. Unger RJ, Feiner JR. Hemodynamic effects of intermittent pneumatic compression of the legs. Anesthesiology 1987; 67: 266-8.

Online access in http://ekja.org 